\title{
A one-year prospective study of morbidity and mortality in first year following a hip fracture among the elderly patients
}

\author{
Alam Penchalaih, Addanki Vijayanand* \\ Department of Orthopaedics, Narayana Medical College, Nellore, Andhra Pradesh, India \\ Received: 12 April 2020 \\ Accepted: 27 April 2020 \\ *Correspondence: \\ Dr. Addanki Vijayanand, \\ E-mail: sujatha2481@gmail.com \\ Copyright: ( $)$ the author(s), publisher and licensee Medip Academy. This is an open-access article distributed under \\ the terms of the Creative Commons Attribution Non-Commercial License, which permits unrestricted non-commercial \\ use, distribution, and reproduction in any medium, provided the original work is properly cited.
}

\begin{abstract}
Background: Hip fractures are one of the most commonest and devastating injuries among the geriatric population. Increasing age, cognitive impairment and higher ASA scores are significantly associated with mortality among the geriatric age group. The objective of this study to evaluate the incidence and causes of morbidity and mortality associated with fracture of the hip in first year after the injury among the elderly population.

Methods: A eighteen months prospective study at Narayana Medical College was conducted among patients aged $>60$ years treated for fracture of hip by arthroplasty and internal fixation. The cases were followed up for one year and mortality and morbidity were evaluated. Associated medical co morbidities were noted for all the cases in the study. Statistical analysis was carried out with IBM SPSS 24.0 and Stata 14 software.

Results: In the study, 76 cases with M:F ratio of 7:12 and mean age of 63.21 \pm 1.4 years were included. Cardio vascular disease and anaemia were common co morbidities. Total mortality percentage in the present study after one year of follow up was $31.58 \%$. Mean age of the cases with death in arthroplasty group was 71 years and 69 years in internal fixation group. Associated medical conditions had a direct relationship with mortality on the patients following surgery for fracture of the hip.

Conclusions: Hemiarthroplasty for fracture of the neck and Internal fixation using dynamic hip screw for trochanteric fracture are still good options in the elderly. Proper post-operative management and follow up management for medical co morbidities provide better functional outcome and good results.
\end{abstract}

Keywords: Hip fracture, Internal fixation, Arthroplasty, Geriatric age

\section{INTRODUCTION}

Hip fractures are one of the most commonest and devastating injuries among the geriatric population. They are one of the most conditions of public health concern among old people, as the condition is associated with crippling deformities if not managed properly. The oftenextreme age and associated co morbidities make the condition most critical and challenging. Hence the outcome depends on multiple factors and associated management plan. These fractures are associated with increased mortality and morbidity than any other fractures among the geriatric age group. As per the report of Wagner
$25 \%$ of the patients with hip fracture become dependent on nursing, $50 \%$ recover to preoperative status and remaining $25 \%$ die within one year of postoperative period. ${ }^{1}$ Increasing age, cognitive impairment and higher ASA scores are significantly associated with mortality among the geriatric age group.

By an estimate, by 2020 almost $20 \%$ of Indian population will be above 60 years and annual incidence of hip fractures will reach about 6 lakhs. Based on current mortality data an estimated $40 \%$ of these cases will die within one year. With changes in the population dynamics and life style related activities, proposed contributing 
factors include genetic factors, malnutrition, less bone mineral content, and environmental factors which include diet and reduced vitamin D levels. ${ }^{2}$

In the present study, the primary objective is to evaluate the incidence and causes of morbidity and mortality associated with fracture of the hip in first year after the injury among the elderly population. The secondary objective was to determine the mortality rate and identify the risk factors of mortality in a one year follow up period among those who have undergone surgery for hip fracture. Understanding these factors and their significance will provide a guide for policy makers and health care service providers to develop guidelines and strategies and prioritize them in reducing the mortality and morbidity of hip fractures among the elderly population.

\section{METHODS}

The present prospective study was conducted at Narayana Medical College, a tertiary care hospital of South India for a period of eighteen months from January 2018 to June 2019. All the patients irrespective of sex presenting with fracture of the hip (femoral neck, transtrochanetric or subtrochanteric) attending the department of orthopaedics and treated by operative procedure with age above 60 years were included in the study. The study protocol was presented before the institutional ethical committee and was approved. The study was conducted as per the guidelines of the committee. Study guidelines and procedure was clearly explained to all the participants and written informed consent was obtained from all the participants. Patients less than 60 years, those with other associated fractures, who were unable to walk before fracture or those with pathological fracture were not included in the study. Patients who were able to follow up for a period of one-year post-surgical procedure were included and cases who lost for follow up or who couldn't be available for follow up were excluded from the study. The morbidity and mortality in the first year after the fracture of the hip were evaluated in the study.

In our study, fracture neck of femur was managed surgically by performing hemiarthroplasty and cases of intertrochanteric fracture were managed by internal fixation using dynamic hip screws (DHS). A separate predesigned questionnaire sheet was prepared for all the cases participating in the study. Profile of patients' data was collected by interviewing and physical examination which include sex, age, date of hospitalization, type and site of fracture, side of fracture, type of treatment plan and any previous history of arthroplasty on hip. The patients were enquired about any associated co morbidities which include hypertension, diabetes, anaemia, cardiovascular disease, airway disease, chronic nervous system disorders, urinary tract infection, thyroid disease and any other metabolic disorders.

Post-surgical evaluation was done and necessary medical advice were given during discharge and all the cases were advised for regular follow-up with first around $30^{\text {th }}$ postoperative day followed by $3^{\text {rd }}$ month, $6^{\text {th }}$ month and one year. The functional results were judged according to the hip rating scale of Merle d' Aubigine. ${ }^{3}$ Roentgenograms of the fractured hips were made at regular intervals and noted till fracture had united or technical failure had occurred. Technical failure was defined as absence of fracture healing with breakage of the implant or dislocation of prosthesis that required reoperation.

\section{Statistical analysis}

The statistical analysis was carried out with IBM SPSS 24.0 and Stata 14 software. Quantitative data were described by their median and standard deviation or by median and interquartile range (IQR). Qualitative data were described by counts and percentage. Descriptive statistics were shown as mean \pm SD or number of cases and percentages, where applicable.

\section{RESULTS}

The present study was conducted by Department of Orthopaedics at Narayana Medical College and Hospital a tertiary care hospital for a period of eighteen months. During the study period a total of 76 cases were enrolled who fulfilled all the inclusion criteria and consented for the study. Majority of the cases in the study were females with 48 in number $(63.16 \%)$ and males only 28 cases $(36.84 \%)$ with male female ratio (M:F) of 7:12. Table 1 summarizes the age distribution of cases in the study with maximum age group between $60-70$ years $(51.32 \%)$ and the rest above 71 years. Mean age of the cases in the study was $63.21 \pm 1.4$ years. The female patients were older than males on average with mean age of $64.28 \pm 2.8$ years and males was only $60.24 \pm 1.9$ years. Mean age of the females was higher in our study. The cases in the study were grouped into two based on the treatment received arthroplasty group and internal fixation group. Mean age of the cases with performed arthroplasty was $61.21 \pm 1.4$ and internal fixation was $65.26 \pm 1.5$ years.

Table 1: Age distribution of cases in the study.

\begin{tabular}{|lll|}
\hline Age distribution (years) & $\mathbf{N}$ & $\%$ \\
\hline $\mathbf{6 0 - 6 5}$ & 21 & 27.63 \\
\hline $\mathbf{6 6 - 7 0}$ & 18 & 23.68 \\
\hline $\mathbf{7 1 - 7 5}$ & 14 & 18.42 \\
\hline $\mathbf{7 6 - 8 0}$ & 12 & 15.79 \\
\hline $\mathbf{8 1}$ & 11 & 14.47 \\
\hline Total & 76 & 100 \\
\hline
\end{tabular}

Table 2 briefs the data of associated co morbidities evaluated preoperatively of the cases in the study. Cardio vascular disease and anaemia were the commonest associated co morbidities $(57.1 \%)$ in the arthroplasty group and anaemia $(61.8 \%)$ in the internal fixation group. Other associated co morbidities were thyroid disorders, chronic lung disorders, diabetes, hypertension and chronic 
nervous system disorders. Most of the cases in the study had more than one co morbid conditions.

Table 2: Associated co-morbidities of the cases in the study.

\begin{tabular}{|lll|}
\hline $\begin{array}{l}\text { Associated medical } \\
\text { conditions }\end{array}$ & $\begin{array}{l}\text { Arth group } \\
\text { N }(\%)\end{array}$ & $\begin{array}{l}\text { IF group } \\
\text { N }(\%)\end{array}$ \\
\hline Cardio vascular disease & $24(57.1)$ & $19(55.9)$ \\
\hline Chronic lung disease & $12(28.6)$ & $11(32.4)$ \\
\hline $\begin{array}{l}\text { Nervous system } \\
\text { disorder }\end{array}$ & $5(11.9)$ & $8(23.5)$ \\
\hline Urinary tract infection & $8(19)$ & $5(14.7)$ \\
\hline Anaemia & $24(57.1)$ & $21(61.8)$ \\
\hline Thyroid disorder & $10(23.8)$ & $14(41.2)$ \\
\hline Metabolic disorder & $6(14.3)$ & $8(23.5)$ \\
\hline
\end{tabular}

IF: Internal fixation, Arth: Arthroplasty.

The total mortality percentage in the present study after one year of follow up was $31.58 \%$, i.e. 24 deaths out of total 76 cases. Of the 24 deaths, 14 cases $(33.33 \%)$ were of arthroplasty group and 10 cases $(29.41 \%)$ were from internal fixation group. Majority of the deaths were recorded in the first month in both the groups. Eleven deaths in arthroplasty and nine deaths in internal fixation group were recorded by the end of sixth month among the cases of the study. The mean age of the cases with death in arthroplasty group was 71 years and 69 years in internal fixation group (Figure 1).

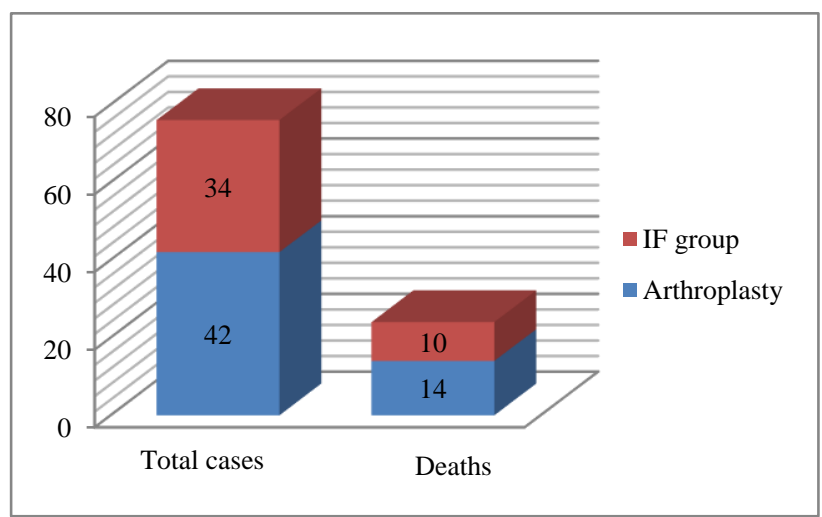

Figure 1: Distribution of cases and deaths in both the groups.

Table 3: Mortality in different age groups and associated medical conditions.

\begin{tabular}{|c|c|c|c|c|c|c|c|c|c|c|}
\hline \multirow{2}{*}{$\begin{array}{l}\text { Condition } \\
\text { Pre-existing } \\
\text { medical } \\
\text { condition }\end{array}$} & \multicolumn{2}{|c|}{ 60-65 years } & \multicolumn{2}{|c|}{ 66-70 years } & \multicolumn{2}{|c|}{$71-75$ years } & \multicolumn{2}{|c|}{ 76-80 years } & \multicolumn{2}{|c|}{$>81$ years } \\
\hline & $\begin{array}{l}\text { Arthro } \\
\text { plasty }\end{array}$ & $\begin{array}{l}\text { IF } \\
\text { group }\end{array}$ & $\begin{array}{l}\text { Arthro } \\
\text { plasty }\end{array}$ & $\begin{array}{l}\text { IF } \\
\text { group }\end{array}$ & $\begin{array}{l}\text { Arthro } \\
\text { plasty }\end{array}$ & $\begin{array}{l}\text { IF } \\
\text { group }\end{array}$ & $\begin{array}{l}\text { Arthro } \\
\text { plasty }\end{array}$ & $\begin{array}{l}\text { IF } \\
\text { group }\end{array}$ & $\begin{array}{l}\text { Arthro } \\
\text { plasty }\end{array}$ & $\begin{array}{l}\text { IF } \\
\text { group }\end{array}$ \\
\hline $\begin{array}{l}\text { Cardio } \\
\text { vascular } \\
\text { disease }\end{array}$ & 2 & 1 & 1 & 1 & 2 & 0 & 1 & 1 & 1 & 0 \\
\hline $\begin{array}{l}\text { Chronic lung } \\
\text { disease }\end{array}$ & 1 & 0 & 2 & 2 & 0 & 1 & 0 & 0 & 0 & 0 \\
\hline $\begin{array}{l}\text { Nervous } \\
\text { system } \\
\text { disorder }\end{array}$ & 1 & 1 & 1 & 2 & 1 & 1 & 1 & 1 & 1 & 0 \\
\hline UTI & 0 & 0 & 0 & 0 & 1 & 0 & 0 & 0 & 0 & 0 \\
\hline Anaemia & 2 & 2 & 2 & 1 & 1 & 2 & 1 & 2 & 0 & 0 \\
\hline $\begin{array}{l}\text { Thyroid } \\
\text { disorder }\end{array}$ & 0 & 1 & 1 & 0 & 0 & 1 & 0 & 1 & 0 & 0 \\
\hline Diabetes & 1 & 1 & 1 & 1 & 1 & 1 & 2 & 1 & 1 & 0 \\
\hline
\end{tabular}

Table 4: Relationship between age and mortality of cases in the study.

\begin{tabular}{|lllllll|}
\hline $\begin{array}{l}\text { Age group } \\
\text { (years) }\end{array}$ & \multicolumn{2}{l}{ Arthroplasty group } & \multicolumn{4}{l|}{ Internal fixation group } \\
\hline $\mathbf{6 0 - 6 5}$ & Total patients & No of deaths & $\mathbf{\%}$ & Total patients & No of deaths & \% \\
\hline $\mathbf{6 6 - 7 0}$ & 10 & 4 & 40 & 11 & 4 & 36.4 \\
\hline $\mathbf{7 1 - 7 5}$ & 9 & 3 & 33.3 & 9 & 3 & 33.3 \\
\hline $\mathbf{7 6 - 8 0}$ & 10 & 3 & 30 & 4 & 2 & 50 \\
\hline$>\mathbf{8 1}$ years & 7 & 2 & 28.6 & 5 & 1 & 20 \\
\hline
\end{tabular}

Table 3 clearly explains the association of co morbidities with age in relation with mortality among the cases in the study. In our study, a clear association was noticed with cardio vascular disease, lung disorders, anaemia and nervous system disorders with respect to their survival rates. A greater mortality rate was observed in these patients than within the patients without the condition. There was statistically significant lower survival rate among the patients with co morbidities (anaemia, cardiovascular disease, lung disease and nervous system 
disorder) than with diabetes, UTI and thyroid disorder. The associated medical conditions had a direct relationship with mortality on the patients following surgery for fracture of the hip.

Table 5: Post-operative complications and rate of mortality in both groups.

\begin{tabular}{|lllll|}
\hline \multirow{2}{*}{ Complication } & Arthroplasty & & Internal fixation & \\
\cline { 2 - 4 } & Cases & Deaths & Cases & Deaths \\
\hline Pressure sore & 4 & 2 & 4 & 1 \\
\hline Pneumonia & 5 & 3 & 1 & 1 \\
\hline Dislocation & 2 & 0 & 0 & 0 \\
\hline Mechanical failure & 2 & 1 & 6 & 4 \\
\hline Post-operative deep infection & 4 & 2 & 3 & 2 \\
\hline
\end{tabular}

Table 6: Final functional results as per hip rating scale of Marle d'Aubinge.

\begin{tabular}{|lllll|}
\hline & Arthroplasty & \multicolumn{2}{c|}{ Internal fixation } \\
\hline Excellent & $\mathbf{6}$ months & $\mathbf{1 2}$ months & $\mathbf{6}$ months & $\mathbf{1 2}$ months \\
\hline Very good & 10 & 9 & 8 & 8 \\
\hline Good & 8 & 8 & 5 & 5 \\
\hline Fair/poor & 6 & 6 & 5 & 5 \\
\hline Total & 7 & 5 & 5 & 4 \\
\hline
\end{tabular}

Table 4 states that incidence of death in post-operative period had a direct relationship with age among the cases with arthroplasty deaths were higher in lower age group in internal fixation group than compared with arthroplasty group. In our study, contrary finding observed was the percentage of deaths in cases with $>81$ years was less in both arthroplasty (33.3\%) and internal fixation (20\%) group. The reason can be explained by in cases above 81 years, majority were not associated with anaemia and co morbidities in our study.

Table 5 summarizes the post-operative complications and mortality rate among the cases in both the groups. Mortality was high in those cases that developed complications following surgery in both the groups. Associated age and co morbidities definitely have a significant association with development of complications and mortality. Complications developed in both the groups, but mechanical failure was more in internal fixation group and pneumonia was higher in arthroplasty group. Dislocation was not observed in cases operated for internal fixation. Table 6 explains the final functional results of the cases who survived after surgery as per hip rating scale of Marle d'Aubinge. Excellent results and outcome were observed in 10 cases by the end of six months and nine cases by the end of one year in cases of arthroplasty, and only five cases were having poor result by the end of 12 months. In cases of internal fixation, eight cases had excellent result by the end of six months and only four cases had poor outcome by the end of one year.

\section{DISCUSSION}

Fractures of the hip are a cause of severe morbidity and mortality among the geriatric population. The cause of these fracture in this age group are mostly traumatic.
Depending upon the site of fracture the patients were grouped as arthroplasty group with fracture neck of femur and internal fixation with trochanteric fracture. The study period was for 18 months and 76 patients who fulfilled the inclusion criteria were enrolled and morbidity and mortality of these patients were observed. In our present study, majority of the cases were females which clearly indicates post-menopausal hormonal and metabolic disturbances play a crucial role in fragility of the bones. This finding of our study was on par with various epidemiological and clinical studies in India and western literature. ${ }^{4}$ Literature from the western countries report that age of the patients with fractures of the hip is more than the people from Indian population. This finding is common to both trochanteric and fracture neck of femur. This is explained by the reason that Indian population is unique in many ways and is predisposed with high risk of osteoporosis and osteoporotic hip fractures throughout the world. The fractures of the hip reported in our study are comparable with several other Indian studies Gupta et al 66 years of mean age. ${ }^{5}$

Anaemia and cardiovascular disease were the most common associated co morbidities of the cases in the study. Findings of our study were on par with the findings of Parker and Guruswamy who reported anaemia as the most common condition with cardio vascular disorder as the next most common co morbid condition, associated with diabetes, hypertension and thyroid disease. ${ }^{6}$ Most of cases of anaemia were managed by blood transfusion before surgery and newly diagnosed cases of cardio vascular diseases were managed and evaluated for surgical fitness. Only those cases fit for surgery were operated and discharged after the co morbidities were managed effectively. Cases after discharge neglected the co morbidities and this might be one of the major reasons for 
mortality and morbidity after surgery. No death was recorded during surgery.

The mortality rates among geriatric population shows that hip fractures have a real and important influence on the survival especially if comparisons are made with cases without hip fractures. According to different studies, mortality of hip fracture among geriatric population range from 14 to $36 \%$ in west and also Indian population. The total mortality percentage in the present study after one year of follow up was $31.58 \%$ which is in range with other studies. ${ }^{7,8}$ Incidence of deaths in the post-operative period always has a direct relationship with the age of the period where the mean age of death in internal fixation was 2 years less than arthroplasty group in our study. Similar finding was reported in the findings of Richmond et al who reported the age of mortality in internal fixation as 70 years and arthroplasty as 72 years. ${ }^{9}$ The heterogeneity of the population studied the standard of care at study settings, lack of consistency in study designs and statistical analysis used to determine the mortality could make the differences in the study.

Mortality following hip fracture surgery is also dependent upon the post-surgical complication and management of associated co morbidities during follow up period. Mortality was high in those cases that developed complications following surgery in both the groups. Associated age and co-morbidities definitely have a significant association with development of complications and mortality. In the present study, mechanical failure was commonly observed in the arthroplasty and pneumonia in the internal fixation rate. Findings in the study of Sircar et al also explained the same as the major post-operative complication after long term follow up for one year. However, $3-4 \%$ of deep vein thrombosis and $2-4 \%$ of pulmonary embolism was also reported which were not identified in our study because of anti-coagulant therapy. ${ }^{10}$

Various criteria have been used to assess the functional outcome following fracture of hip after surgery. In Indian scenario as our customs demand squatting and sitting cross legged without difficulty. To achieve this as best outcome, full flexion of knee, good range of hip flexion with abduction and external rotation. This is very difficult to achieve even with the best modalities of treatment in geriatric age group. To compare the results of our findings with the west we used hip scoring scale of Marle'd Aubigne. Based on the different rating systems used the final results will vary a little with every system. In the present study, the differences between excellent, very good and good results are minimal and therefore can be collectively grouped as satisfactory results. Sepah et al attributed poor functional results due to pre-existing co morbidities mainly due to anaemia in female population and cardiovascular disease in males. ${ }^{11}$ Few studies reported that delayed weight bearing may be an additional contributing factor in functional outcome following hip surgery. The final outcome is also influenced by development of post-operative complications following post-operative surgery; less the complications better the outcome of the surgery.

\section{CONCLUSION}

In our present study, morbidity and mortality in elderly patients following fracture of hip is significantly high in those with pre-existing co-morbidities. In these patient's mechanical failure of the internal fixation device or the dislocation of the prosthesis increases the risk. Hemiarthroplasty for fracture of the neck and Internal fixation using dynamic hip screw for trochanteric fracture are still good options in the elderly. Proper post-operative management and follow up management for medical co morbidities provide better functional outcome and good results.

\section{Funding: No funding sources \\ Conflict of interest: None declared \\ Ethical approval: The study was approved by the institutional ethics committee}

\section{REFERENCES}

1. Wagner P, Fuentes P, Diaz A, Martinez F, Amenabar $\mathrm{P}$, Schweitzer D, et al. Comparison of complications and length of hospital stay between Orthopedic and Orthogeriatric treatment in elderly patients with a hip fracture. Geriatric Orthopedic Surg Rehabilitation. 2012;3:55-8.

2. Dhanwal DK, Dennison EM, Harvey NC, Cooper C. Epidemiology of hip fracture: worldwide geographic variation. Indian J Orthop. 2011;45:15-22.

3. Aubigne MDR, Cauchoix J, Ramadier JV. Evaluation chiffree de la function de la hanche. Application a l'etude des resultants des operations mobilisatrices de la hanche. Rev Chir Orthop Reparatrice Appar Mot. 1949;35:5-12.

4. Ahuja K, Sen S, Dhanwal D. Risk factors and epidemiological profile of hip fractures in Indian population: A case-control study. Osteoporos Sarcopenia. 2017;3(3):138-48.

5. Gupta A. Osteoporosis in India: the nutritional hypothesis. Natl Med J India. 1996;9:268-74.

6. Parker MJ, Gurusamy K. Internal fixation versus arthroplasty for intracapsular proximal femoral fractures in adults. Cochrane Database Syst Rev. 2006;(4):001708.

7. Cornwall R, Gilbert MS, Koval KJ, Strauss E, Siu AL. Functional outcomes and mortality vary among different types of hip fractures: a function of patient characteristics. Clin Orthop Relat Res. 2004;(425):64-71.

8. Vestergaard P, Rejnmark L, Mosekilde L. Has mortality after a hip fracture increased. J Am Geriatr Soc. 2007;55(11):1720-6.

9. Richmond J, Aharonoff GB, Zuckerman JD, Koval KJ. Mortality risk after hip fracture. J Orthop Trauma. 2003;17(8):2-5. 
10. Sircar P, Godkar D, Mahgerefteh S, Chambers K, Niranjan S, Cucco R. Morbidity and mortality among patients with hip fractures surgically repaired within and after 48 hours. Am J Ther. 2007;14(6):508-13.

11. Sepah JY, Umer M, Khan A, Niazi UKA. Functional outcome, mortality and in-hospital complications of operative treatment in elderly patients with hip fractures in the developing world. Int Orthop. 2010;34:431-5.

Cite this article as: Penchalaih A, Vijayanand A. A one-year prospective study of morbidity and mortality in first year following a hip fracture among the elderly patients. Int J Res Orthop 2020;6:660-5. 